\title{
Identifikasi Keberadaan Air Tanah Menggunakan Metode Geolistrik Resistivitas Konfigurasi Schlumberger (Studi Kasus: Desa Clapar Kabupaten Banjarnegara) ${\text { Muhardia*, Radhitya Perdhanaa }{ }^{a} \text { Nasharuddin }}^{b}$
}

aProdi Geofisika, Universitas Tanjungpura Pontianak bProdi Pendidikan Fisika, Universitas Muhammadiyah Makasar

*Email : muhardi@physics.untan.ac.id

\begin{abstract}
Abstrak
Penelitian tentang keberadaan air tanah telah dilakukan menggunakan metode geolistrik resistivitas konfigurasi Schlumberger. Penelitian ini dilakukan di Desa Clapar Kabupaten Banjarnegara. Akuisisi data menggunakan dua titik pengukuran dengan bentangan hingga 200 meter, dan jarak antar kedua titik pengukuran sebesar 100 meter. Hasil penelitian menunjukkan bahwa sebaran nilai resistivitas secara sounding pada titik pertama sebesar 0,33 - $377 \Omega \mathrm{m}$, dengan kedalaman hingga 70 meter. Keberadaan air tanah pada titik pertama diduga terdapat pada akuifer bebas dengan kedalaman 3,09 - 17,6 meter (ketebalan 14,51 meter), dan akuifer tertekan dengan kedalaman 24,8 - 50,5 meter (ketebalan 25,7 meter). Sedangkan sebaran nilai resistivitas secara sounding pada titik kedua sebesar 7,21 - 1.281 $\Omega \mathrm{m}$, dengan kedalaman hingga 70 meter. Keberadaan air tanah pada titik kedua diduga terdapat pada akuifer bebas dengan kedalaman 5,22 - 9,82 meter (ketebalan 4,6 meter), dan akuifer tertekan dengan kedalaman 37 - 63,9 meter (ketebalan 26,9 meter). Hasil penelitian juga menunjukkan bahwa akuifer bebas diinterpretasi berupa litologi pasir lempungan, sedangkan akuifer tertekan diinterpretasi berupa litologi pasir hingga pasir kerikilan.
\end{abstract}

Kata Kunci : Air Tanah, Akuifer, Desa Clapar, Metode Geolistrik, Schlumberger

\section{Latar Belakang}

Air tanah adalah air di bawah permukaan bumi yang terdapat pada celah dan ruang pori tanah atau batuan[1]. Air tanah terbentuk dari proses hidrologi, tersimpan dan bergerak pada lapisan yang disebut akuifer (aquifer). Air tanah berasal dari air yang meresap melalui permukaan (misalnya air hujan) dan bergerak melaui lapisan bawah permukaan kemudian mengisi celah dan ruang pori yang terdapat pada tanah atau batuan[2]. Air tanah merupakan sumber daya alam yang melimpah karena ketersediaannya di bawah permukaan sangat banyak dan dapat ditemukan hampir di semua tempat.

Air tanah mempunyai peranan yang sangat penting karena pemanfaatannya dibutuhkan dalam kehidupan sehari-hari. Keberadaan air tanah terdapat pada kedalaman yang berbedabeda, karena sangat tergantung pada kondisi geologi setempat. Meskipun ketersediaannya melimpah di bawah permukaan, namun masyarakat perlu mendapatkan informasi tentang keberadaaan air tanah tersebut. Salah satu informasi yang sangat dibutuhkan masyarakat untuk pemanfaatan air tanah adalah tentang kedalamannya di bawah permukaan.

Air tanah umumnya berada pada lapisan akuifer yang memiliki litologi tertentu. Akuifer terdiri dari akuifer bebas (unconfined aquifer) yang relatif dangkal dan akuifer tertekan (confined aquifer) yang relatif dalam[3], seperti pada Gambar 1. Akuifer merupakan lapisan yang berpori, permeable, dan bersifat jenuh, contohnya lapisan pasir yang belum terkonsolidasi, sehingga dapat mengalirkan sekaligus menyimpan air tanah[4]. Di antara kedua lapisan akuifer ini terdapat lapisan akuitar (aquitard) yang bersifat impermeabel, contohnya lapisan lempung.

Permasalahan utama ketersediaan air tanah umumnya disebabkan karena sumur warga yang masih relatif dangkal, sehingga tidak dapat memanfaatkan air tanah pada akuifer tertekan. Sumur warga yang masih dangkal mengalami persoalan yaitu kekeruhan. Oleh sebab itu perlu adanya informasi terkait dengan keberadaan air tanah yang terdapat pada akuifer tertekan. Air tanah pada akuifer tertekan umumnya mempunyai kelebihan yaitu lebih jernih dan persediaannya lebih banyak jika dibandingkan dengan air tanah pada akuifer bebas, sehingga dapat digunakan untuk kepentingan yang lebih luas.

Masyarakat di Desa Clapar Kecamatan Madukara Kabupaten Banjarnegara masih belum memanfaatkan potensi air tanah di daerah tersebut. Penggunaan air bersih masih bersumber dari selain air tanah. Hal ini disebabkan karena belum adanya informasi terkait dengan keberadaan air tanah. Oleh sebab itu, perlu dilakukan identifikasi keberadaan air tanah di Desa Clapar. 


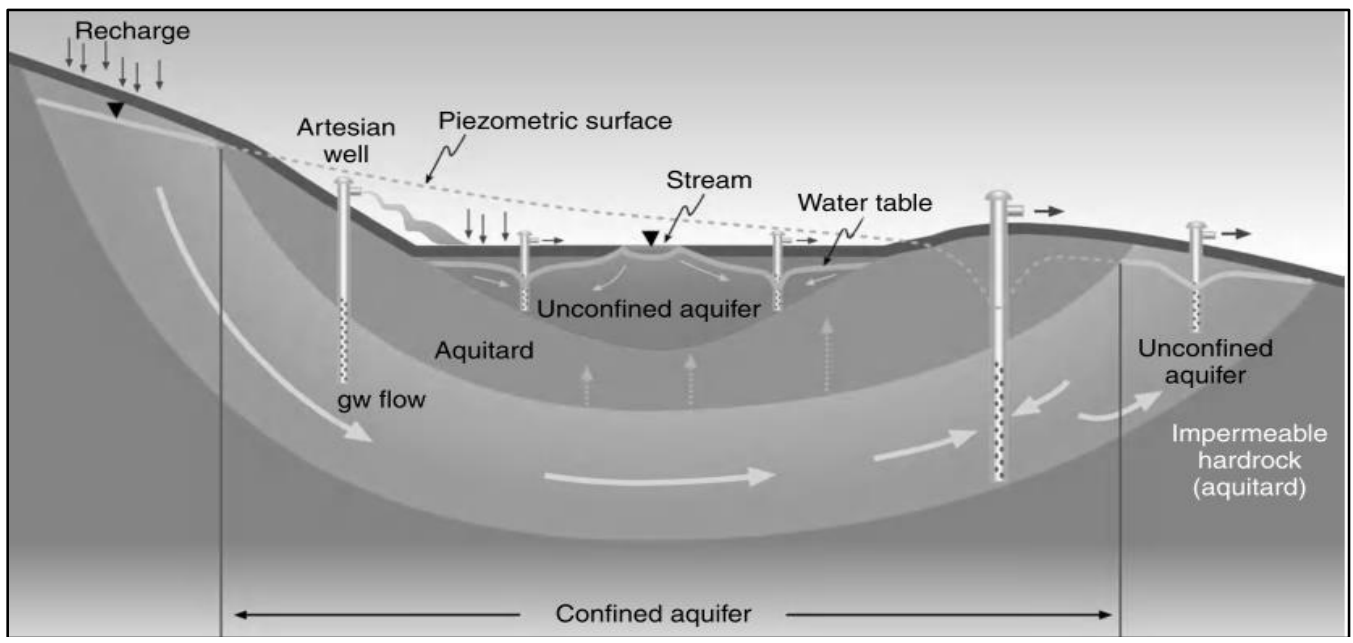

Gambar 1. Skema keberadaan air tanah pada akuifer bebas dan akuifer tertekan[5]

Metode geolistrik telah banyak digunakan untuk menyelidiki lapisan akuifer, baik yang dilakukan secara sounding [4,5] maupun mapping[6,7]. Identifikasi keberadaan air tanah pada penelitian ini berdasarkan sebaran nilai resistivitas. Metode ini dipilih karena air tanah umumnya bersifat konduktif dan mempunyai nilai resistivitas yang lebih kecil. Sedangkan penggunaan konfigurasi Schlumberger diharapkan mampu mengidentifikasi sebaran resistivitas secara sounding, sehingga dapat menduga keberadaan air tanah pada akuifer tertekan.

\section{Metodologi}

Penelitian dilakukan di bagian Tenggara Desa Clapar Kecamatan Madukara Kabupaten Banjarnegara Propinsi Jawa Tengah (kotak merah), seperti pada Gambar 2. Akuisisi data dilakukan pada dua titik pengukuran. Titik pertama (VES01) berada pada koordinat 7020'39,48" LS dan 109045'43,28” BT, sedangkan titik kedua (VES02) berada pada koordinat 0032'28,4" LU dan 82038'8,7" BT.

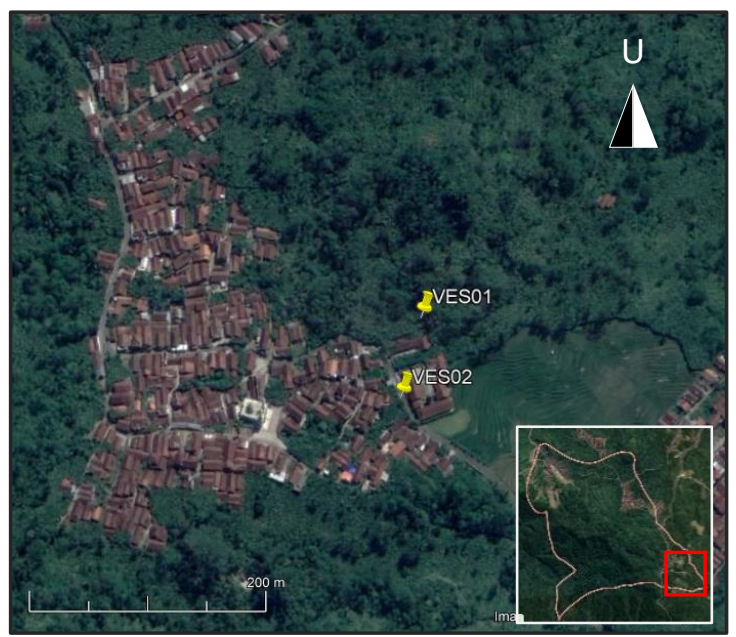

Gambar 2. Posisi titik pengukuran pada lokasi penelitian
Prinsip dari metode geolistrik yaitu dengan memanfaatkan injeksi arus yang dialirkan ke lapisan bawah permukaan. Aliran arus yang melewati lapisan bawah permukaan akan dijadikan acuan dalam mengidentifikasi nilai resistivitas bahan pada lapisan yang dilewatinya[10]. Ilustrasi aliran arus diperlihatkan pada Gambar 3 berikut.

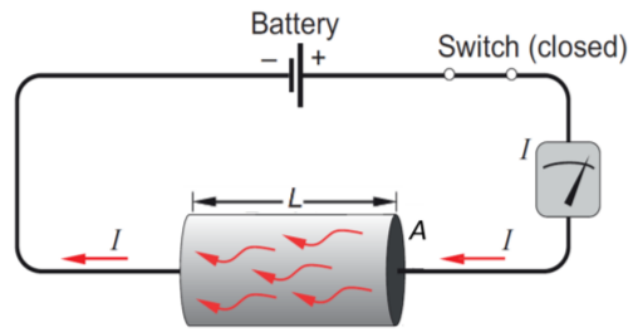

Gambar 3. Ilustrasi arus listrik yang mengalir pada medium berbentuk silinder[11]

Jika arus listrik yang mengalir pada sebuah medium berbentuk silinder, maka resistansi medium dapat dirumuskan dengan persamaan berikut.

$$
R=\frac{V}{I}
$$

Sedangkan nilai resistivitas bahan pada medium dapat dirumuskan dengan persamaan berikut.

$$
\rho=R \frac{A}{L}
$$

Keterangan :

$V=$ beda potensial (Volt)

$R=\operatorname{resistansi}(\Omega)$

$I \quad=$ arus listrik (Ampere)

$\rho=$ resistivitas bahan $(\Omega \mathrm{m})$

$A=$ luas penampang medium $\left(\mathrm{m}^{2}\right)$

$L=$ panjang medium $(\mathrm{m})$ 
Penelitian ini menggunakan metode geolistrik resistivitas konfigurasi Schlumberger, karena mempunyai kelebihan yaitu dapat mengidentifikasi keberadaan air tanah pada lapisan yang cukup dalam[12]. Penelitian ini menggunakan alat Resistivitymeter dilengkapi dengan empat buah elektroda yang dipasang seperti pada Gambar 4. Dua buah elektroda arus (A dan B) dipasang dengan jarak $X_{A B}$, sedangkan dua buah elektroda potensial (M dan $\mathrm{N}$ ) dipasang dengan jarak $X_{M N}$. Pada penelitian ini jarak $X_{A B}$ sebesar 0,2 meter, dan dilakukan proses sifting sebanyak 5 kali hingga sejauh 12 meter, sedangkan jarak $X_{A B}$ dibentangkan hingga sejauh 200 meter.

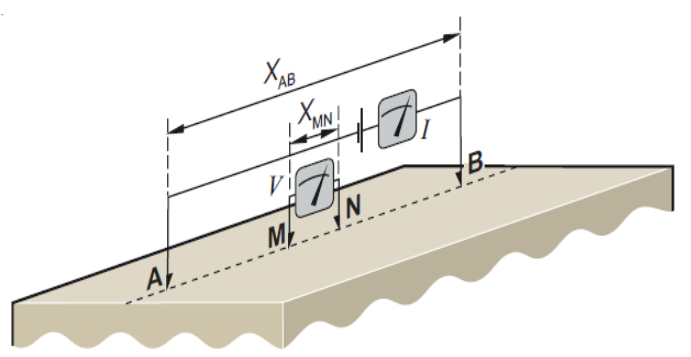

Gambar 4. Susunan elektroda dengan konfigurasi Schlumberger[11]

Data yang diperoleh di lapangan berupa arus listrik dan beda potensial (tegangan). Kemudian dilakukan perhitungan untuk memperoleh nilai resistansi dan resistivitas. Namun resistivitas yang diperoleh dari pengukuran adalah resistivitas semu (apparent resistivity), karena bawah permukaan bumi umumnya bersifat berlapis. Resistivitas semu $\rho_{a}(\Omega \mathrm{m})$ pada konfigurasi Schlumberger dapat dirumuskan dengan persamaan berikut[13].

$$
\rho_{a}=\pi \frac{\left[\left(\frac{1}{2} X_{A B}\right)^{2}-\left(\frac{1}{2} X_{M N}\right)^{2}\right]}{X_{M N}} \frac{V}{I}
$$

Kemudian dilakukan proses pengolahan hasil perhitungan dengan menggunakan software IPI2WIN sehingga diperoleh kurva matching. Kurva ini dapat dijadikan acuan dalam menentukan jumlah lapisan dan sebaran nilai resistivitas semu terhadap kedalaman[14]. Proses inversi dilakukan untuk memperoleh sebaran resistivitas yang sebenarnya (true resistivity) terhadap kedalaman pada setiap lapisan.

Nilai resistivitas yang diperoleh dijadikan acuan untuk mengidentifikasi keberadaan air tanah yang terdapat pada akuifer bebas dan akuifer tertekan. Nilai resistivitas diinterpretasi berdasarkan pendekatan nilai resistivitas pada Tabel 1 berikut.
Tabel 1. Nilai resistivitas pada tanah/batuan dan air tanah[12,13]

\begin{tabular}{ll}
\hline Material & $\begin{array}{l}\text { Resistivitas } \\
(\boldsymbol{\Omega m})\end{array}$ \\
\hline Batupasir & $1-6,4 \times 10^{8}$ \\
Pasir & $1-1.000$ \\
Kerikil & $100-600$ \\
Lempung & $1-100$ \\
Lempung basah (tidak & \\
terkonsolidasi) & 20 \\
Alluvium & $10-800$ \\
Air asin & 0,2 \\
Air tanah & $0,5-300$ \\
Air tanah (batuan beku) & $30-150$ \\
Air tanah (batuan sedimen) & $>1$ \\
\hline
\end{tabular}

\section{Hasil dan Pembahasan}

Kurva matching yang diperoleh pada titik pertama (VES01) menunjukkan hubungan antara nilai resistivitas semu (sumbu vertikal) dan bentangan elektroda arus (sumbu horizontal). Gambar 5 menunjukkan kesesuaian antara data hasil observasi dengan hasil kalkulasi. Berdasarkan sebaran nilai resistivitas secara sounding, diidentifikasi tujuh lapisan pada titik pertama hingga kedalaman 70 meter, dengan sebaran nilai resistivitas 0,33 - $377 \Omega \mathrm{m}$.

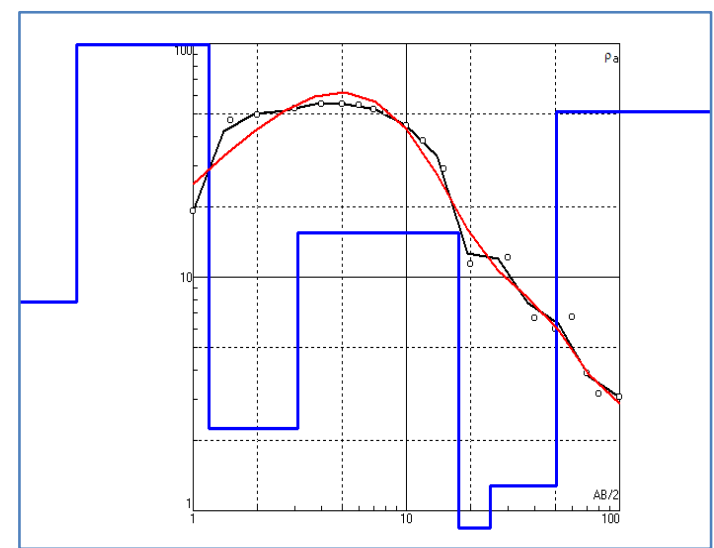

Gambar 5. kurva matching pada titik pertama

Adapun sebaran nilai resistivitas secara sounding dari hasil pengukuran pada titik pertama seperti diperlihatkan pada Tabel 2 .

Tabel 2. Hasil pengukuran pada titik pertama

\begin{tabular}{ccc}
\hline lapisan & $\begin{array}{c}\text { Resistivitas } \\
(\mathbf{\Omega m})\end{array}$ & $\begin{array}{c}\text { Kedalaman } \\
(\mathbf{m})\end{array}$ \\
\hline 1 & 7,87 & $0-0,28$ \\
2 & 377 & $0,28-1,19$ \\
3 & 2,25 & $1,19-3,09$ \\
4 & 15,5 & $3,09-17,6$ \\
5 & 0,33 & $17,6-24,8$ \\
6 & 1,28 & $24,8-50,5$ \\
7 & 50,9 & $50,5-70$ \\
\hline
\end{tabular}


Akuifer pada titik pertama diduga terdapat pada lapisan keempat dan keenam. Akuifer bebas diduga berada pada lapisan keempat dengan nilai resistivitas $15,5 \Omega \mathrm{m}$ dan kedalaman 3,09 - 17,6 meter (ketebalan 14,51 meter). Keberadaan air tanah dangkal terdapat pada lapisan yang diinterpretasi berupa litologi pasir lempungan[16]. Sedangkan akuifer tertekan diduga berada pada lapisan keenam dengan nilai resistivitas $1,28 \Omega \mathrm{m}$ dan kedalaman 24,8 meter hingga 50,5 meter (ketebalan 25,7 meter). Keberadaan air tanah dalam terdapat pada lapisan yang diinterpretasi berupa litologi pasir.

Kurva matching yang diperoleh pada titik kedua (VES02) menunjukkan hubungan antara nilai resistivitas semu (sumbu vertikal) dan bentangan elektroda arus (sumbu horizontal). Gambar 6 menunjukkan kesesuaian antara data hasil observasi dengan hasil kalkulasi. Berdasarkan sebaran nilai resistivitas secara sounding, diidentifikasi delapan lapisan pada titik kedua hingga kedalaman 70 meter, dengan sebaran nilai resistivitas $7,21-1.281 \Omega \mathrm{m}$.

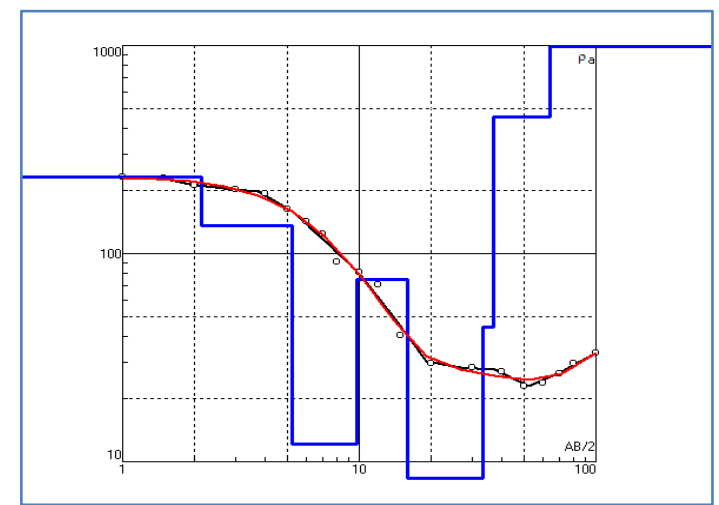

Gambar 6. kurva matching pada titik kedua

Adapun sebaran nilai resistivitas secara sounding dari hasil pengukuran pada titik kedua seperti diperlihatkan pada Tabel 3.
Tabel 3. Hasil pengukuran pada titik kedua

\begin{tabular}{ccc}
\hline Lapisan & $\begin{array}{c}\text { Resistivitas } \\
(\mathbf{\Omega m})\end{array}$ & $\begin{array}{c}\text { Kedalaman } \\
\mathbf{( m )}\end{array}$ \\
\hline 1 & 232 & $0-2,16$ \\
2 & 136 & $2,16-5,22$ \\
3 & 12,1 & $5,22-9,82$ \\
4 & 75,3 & $9,82-16$ \\
5 & 7,21 & $16-33,1$ \\
6 & 44,4 & $33,1-37$ \\
7 & 453 & $37-63,9$ \\
8 & 1.281 & $63,9-70$ \\
\hline
\end{tabular}

Akuifer pada titik kedua diduga terdapat pada lapisan ketiga dan ketujuh. Akuifer bebas diduga berada pada lapisan ketiga dengan nilai resistivitas 12,1 $\Omega \mathrm{m}$ dan kedalaman 5,22 - 9,82 meter (ketebalan 4,6 meter). Keberadaan air tanah dangkal terdapat pada lapisan yang diinterpretasi berupa litologi pasir lempungan[16]. Sedangkan akuifer tertekan diduga berada pada lapisan ketujuh dengan nilai resistivitas $453 \Omega \mathrm{m}$ dan kedalaman 37 - 63,9 meter (ketebalan 26,9 meter). Keberadaan air tanah dalam terdapat pada lapisan yang diinterpretasi berupa litologi pasir kerikilan.

Sebaran resistivitas secara sounding pada kedua titik pengukuran juga dapat disajikan dengan penampang dua dimensi seperti pada Gambar 7. Hasil pengukuran sebaran resistivitas semu menunjukkan bahwa adanya perubahan nilai yang semakin kecil terhadap pertambahan kedalaman. Lapisan bawah permukaan pada titik pertama (VES01) berdasarkan sebaran resistivitas yang sebenarnya ditunjukkan pada penampang sebelah kiri yaitu jarak 0 - 50 meter. Sedangkan lapisan bawah permukaan pada titik kedua (VES02) berdasarkan sebaran resistivitas yang sebenarnya ditunjukkan pada penampang sebelah kanan yaitu jarak 50 - 100 meter.

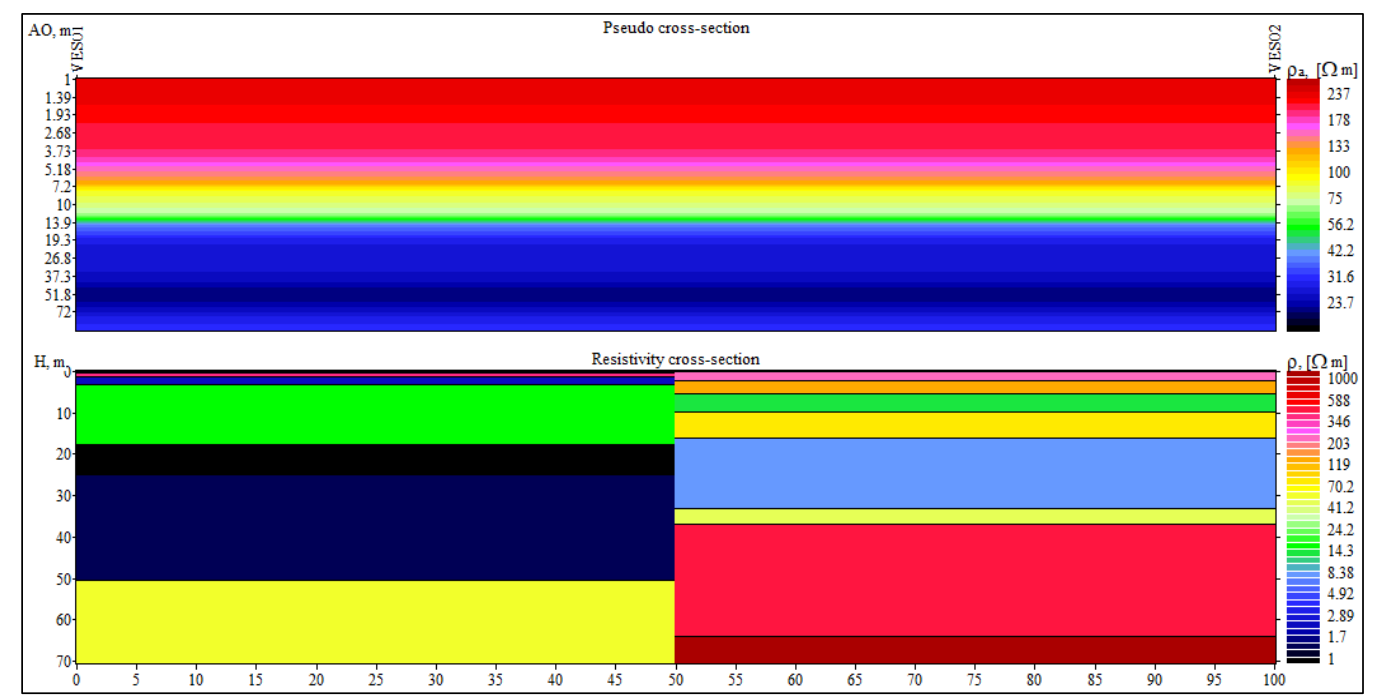

Gambar 7. Penampang 2D resistivitas semu (atas) dan resistivitas yang sebenarnya (bawah) 
Lapisan akuifer bebas pada titik pertama digambarkan dengan warna hijau dan lapisan akuifer tertekan digambarkan dengan warna biru tua. Sedangkan lapisan akuifer bebas pada titik kedua digambarkan dengan warna hijau dan lapisan akuifer tertekan digambarkan dengan warna merah cerah. Nilai resistivitas yang menggambarkan akuifer tertekan pada kedua titik pengukuran relatif berbeda, hal ini disebabkan karena adanya perbedaan secara litologi. Pada titik pertama diinterpretasi berupa litologi pasir, sedangkan pada titik kedua diinterpretasi berupa litologi pasir dengan sedikit kerikil (pasir kerikilan).

Akuifer bebas diinterpretasi berupa litologi pasir lempungan. Litologi pasir dengan sedikit lempung mempunyai sifat berpori dan permeabel, sehingga dapat menyimpan dan meloloskan air tanah[4]. Akuifer tertekan pada titik pertama diinterpretasi berupa litologi pasir, sedangkan titik kedua diinterpretasi berupa litologi pasir kerikilan. Akuifer diidentifikasi mempunyai nilai resistivitas yang relatif kecil karena lapisan tersebut mengandung air tanah dan bersifat jenuh. Air tanah umumnya bersifat konduktif sehingga mudah menghantarkan arus listrik. Akuifer bebas dan akuifer tertekan dibatasi oleh lapisan lain yang disebut akuitar, dan diinterpretasi berupa lapisan lempung dengan nilai resistivitas yang relatif kecil[17] dan bersifat impermeabel, sehingga tidak dapat meloloskan air tanah.

\section{Kesimpulan}

Sebaran nilai resistivitas secara sounding pada titik pertama (VES01) yaitu 0,33 - $377 \Omega \mathrm{m}$ hingga kedalaman 70 meter. Keberadaan air tanah diduga terdapat pada akuifer bebas dengan kedalaman 3,09 - 17,6 meter (ketebalan 14,51 meter), dan akuifer tertekan dengan kedalaman 24,8 - 50,5 meter (ketebalan 25,7 meter). Sedangkan sebaran nilai resistivitas secara sounding pada titik kedua (VES02) yaitu 7,21 - $1.281 \Omega \mathrm{m}$ hingga kedalaman 70 meter. Keberadaan air tanah diduga terdapat pada akuifer bebas dengan kedalaman 5,22 - 9,82 meter (ketebalan 4,6 meter), dan akuifer tertekan dengan kedalaman 37 - 63,9 meter (ketebalan 26,9 meter). Akuifer bebas di lokasi penelitian diinterpretasi berada pada litologi pasir lempungan, sedangkan akuifer tertekan diinterpretasi berada pada litologi pasir hingga pasir kerikilan.

\section{Daftar Pustaka}

[1] Heath, B. R. C., Basic Ground-Water Hydrology, 4th Ed., North Carolina: USGS, 1982.
[2] Tood, D. K. and Mays, L. W. Groundwater Hydrogeology, 3rd Ed., California: USGS, 2005.

[3] Darsono, Identifikasi Akuifer Dangkal dan Akuifer Dalam dengan Metode Geolistrik (Kasus: di Kecamatan Masaran), Indonesian Journal of Applied Physics, 1(1), 40-49, 2016.

[4] Darsono and Darmanto, D., Identifikasi Keberadaan Lapisan Akuifer Tertekan (Confined Aquifer) Berdasarkan Data Geolistrik (Studi Kasus: Desa Sambirejo Kecamatan Plupuh Kabupaten Sragen), Indonesian Journal of Applied Physics, 9(1), 46-53, 2019.

[5] Lehr, J. H. and Keeley, J., Water Encyclopedia-Ground Water, Canada: Willey-Interscience, 2005.

[6] Nurfalaq, A., Nawir, A., Manrulu, R. H., and Umar, E. P., Identifikasi Akuifer Daerah Pallantikang Kabupaten Jeneponto dengan Metode Geolistrik, Jurnal Fisika Flux, 15(2), 117-127, 2018.

[7] Sutasoma, M., Azhari, A. P., and Arisalwadi, M., Identifikasi Air Tanah dengan Metode Geolistrik Resistivitas Konfigurasi Schlumberger di Candi Dasa Propinsi Bali, Jurnal Fisika dan Pendidikan Fisika, 3(2), 58-65, 2018.

[8] Gijoh, O. T., As'ari, A., and Pasau, G., Identifikasi Akuifer Air Tanah Menggunakan Metode Geolistrik Tahanan Jenis Konfigurasi Dipol-dipol di Masjid Kampus Universitas Sam Ratulangi," Jurnal MIPA UNSRAT, 6(1), 17-20, 2017.

[9] Rohmah, S. A., Maryanto, S., and Susilo, A., Identifikasi Air Tanah Daerah Agrotechno Park Cangar Batu Jawa Timur Berdasarkan Metode Geolistrik Resistivitas, Jurnal Fisika dan Aplikasinya, 14(1), 5-11, 2018.

[10] Everett, M. E., Near-Surface Applied Geophysics. New York: Cambridge University Press, 2013.

[11] Dentith, M. and Mudge, S., Geophysics for the Mineral Exploration Geoscientist. New York: Cambridge University Press, 2014.

[12] Fitrianto, T. N., Supriyadi, S., Taufiq, U. A., Mukromin, T. M. and Wardana, A. P., Identifikasi Potensi Air Tanah Menggunakan Metode Geolistrik Resistivitas Konfigurasi Schlumberger di Kelurahan Bapangsari Kecamatan Bagelen Kabupaten Purworejo, Jurnal Fisika Flux, 15(2), 100-104, 2018. 
[13] Milsom, J., Field Geophysics, 3rd Ed., England: Wiley, 2002.

[14] Telford, W. M., Geldart, L. P., and Sheriff, R. E., Applied Geophysics, 2nd Ed., New York: Cambridge University Press, 1990.

[15] Saad, R., Nawawi, and Mohamad, E. T., Groundwater Detection in Alluvium Using 2-D Electrical Resistivity Tomography Groundwater Detection in Alluvium Using 2-D Electrical Resistivity Tomography (ERT), Electronic Journal of Geotechical Engineering, 17, 369-376, 2012.

[16] Muhardi and Wahyudi, Identifikasi Litologi Area Rawan Longsor di Desa ClaparBanjarnegara Menggunakan Metode Geolistrik Resistivitas Konfigurasi Schlumberger, Jurnal Fisika, 9,(2), 52-59, 2019.

[17] Kurniawan, A., Sifat Resistivitas Rendah Mineral Lempung, Masyarakat Ilmu Bumi Indonesia, 1(2), 1-9, 2014. 